\title{
ASSET MANAGEMENT OF ENERGY COMPANY BASED ON RISK-ORIENTED STRATEGY
}

\author{
LAZAR D. GITELMAN ${ }^{1}$, MIKHAIL V. KOZHEVNIKOV ${ }^{1}$, GALINA S. CHEBOTAREVA ${ }^{1}$ \\ \& OLGA A. KAIMANOVA ${ }^{2}$ \\ ${ }^{1}$ Academic Department of Energy and Industrial Enterprises Management Systems, \\ Ural Federal University, Russia \\ ${ }^{2}$ Federal Grid Company of Unified Energy System, Russia
}

\begin{abstract}
Repairs and maintenance of energy assets can be carried out in a variety of ways, which are usually based on indicators of reliability and efficiency. Due to the transition to a digital energy paradigm and implementation of intelligent diagnostic tools for technical condition of the equipment, it is advisable to carry out asset management with additional tools to consider operational and economic risks, as well as to predict the integrated efficiency of energy objects. This paper presents an overview of progressive strategies for energy asset management currently used in global practice. The analysis of approaches to asset management developed by one of the largest Russian generating and grid utilities is carried out. The authors developed several methodological recommendations for the identification of priority objects for technical maintenance and repair, ranked based on the type of equipment, risk of failure, predictiveness of defects, the undersupply of energy in emergency situations, types and cost of remediation and reputation losses of the energy business. Proposals for energy companies to implement a risk-based assets management strategy in units operating energy facilities are formulated.
\end{abstract}

Keywords: energy, digital energy, energy assets, repair, technical maintenance, risk, progressive strategy, efficiency, reliability, smart grid.

\section{INTRODUCTION}

Asset management in the energy sector is a complex process, the outcomes of which are, on the one hand, better quality and greater reliability of the services being provided and, on the other hand, optimization of energy infrastructure maintenance costs [1], [2].

International Organization for Standardization (ISO) 55000 [3] covers a broad variety of assets, including financial, information, human ones. This paper focuses on physical (production) assets of energy companies. Production asset management is defined by the authors as a combination of investment, technical, economic and financial management decisions that cover the entire lifecycle of units of fixed assets and are implemented in the interest of the company, consumers, and society under the guidance of operation controls and in compliance with public regulators' instructions [4]. In the context of a complex and capital intensive industry like power engineering that is currently going through digital transformation, production asset management plays a key role in ensuring stable uninterrupted power supply and improving the performance of investment projects that are aimed at technological modernization of the energy sector.

Modern production asset management systems are built upon the principle of equipment maintenance based on condition, the probability of failure and significance rating of each unit in the process of electricity transmission and distribution. Risk-based asset management that takes into account economic, environmental and reputational risks makes it possible to considerably reduce the risk of a power outage [5].

Traditional time-based preventive maintenance strategies imply scheduled preventive efforts that are aimed at preventing progressing wear and tear on equipment and ensuring its operational availability at all times. This principle is hardly applicable in the case of a high 
level of fixed assets deterioration and a considerable risk of unplanned failures, resulting in additional mitigation costs and losses incurred due to the non-delivery of electricity and heat to end users.

The most advanced production asset management systems use risk-based strategies and imply equipment maintenance based on condition, the probability of failure and significance rating of each unit in the process of electricity transmission and distribution [6]. The risk is calculated on the basis of asset condition projections that incorporate operational data rather than on following an actual failure. This ensures a higher confidentiality level thanks to the lifting of restrictions on equipment repairs within the framework of time-based preventive maintenance programs.

The presented problem dictates the following structure of this paper. Section 2 is a review of methods, strategies and operating models of energy asset management that are in use in various countries. Section 3 describes production asset management practices in the Russian energy sector and examines the case of Federal Grid Company of Unified Energy System (Public Joint-Stock Company "Federal Grid Company of Unified Energy System" (PJSK "FGC UES")), one of Russia's biggest grid companies, that showcases methodological peculiarities and practical aspects of adopting an asset management system. The Conclusion Section summarizes the findings and identifies directions for further research.

\section{REVIEW OF STRATEGIES FOR ENERGY ASSET MANAGEMENT}

Energy asset management is associated with a high degree of uncertainty due to a mix of economic factors (e.g., return on investment, revenue cap regulation) as well as a number of technical aspects, such as the level of technology advancement, asset operational efficiency. As a result, pioneering strategies and operating models of energy asset management are based on the multiple scenario approach and on designing a portfolio of alternatives and take into account the principles of sustainability, expediency, adequacy and risk management [7]-[9]. The list of the most common energy asset management strategies typically includes [7], [10][16]:

- $\quad$ Condition-based maintenance (CBM);

- Reliability-centred maintenance (RCM);

- $\quad$ Risk-based maintenance (RBM).

A CBM strategy envisages specific actions on an asset (abandonment, rehabilitation or replacement) when the condition of the energy asset threatens network reliability [17]. Unlike $\mathrm{CBM}, \mathrm{RCM}$ is a more advanced maintenance strategy that factors in a combination of aspects, including the timing cycle, conditions for maintenance, failure modes, effects and criticality analysis [11], [18] etc. An example of an RCM strategy is intelligent RCM analysis (IRCMA) [13]. The idea for IRCMA is based on the fact that the historical records of RCM analysis on energy assets can be referenced and used for the current RCM analysis of a new similar item [13].

Today, strategies that are centered on risk-based assessment are acknowledged by practitioners as the most effective ones for energy asset management [7], [19], [20].

\subsection{RBM-strategy for asset management in energy companies}

Under the RBM strategy, policies and schedules for energy asset maintenance are designed with the help of a model that takes into account both the current condition of the asset and the probability of a failure and the aftermath of an incident (the factor of asset criticality). 
The two-dimensional collection of the indicators is visualized by means of a risk map (Fig. 1) [21]. Each of the four quadrants is a place where a specific energy asset management strategy is designed.

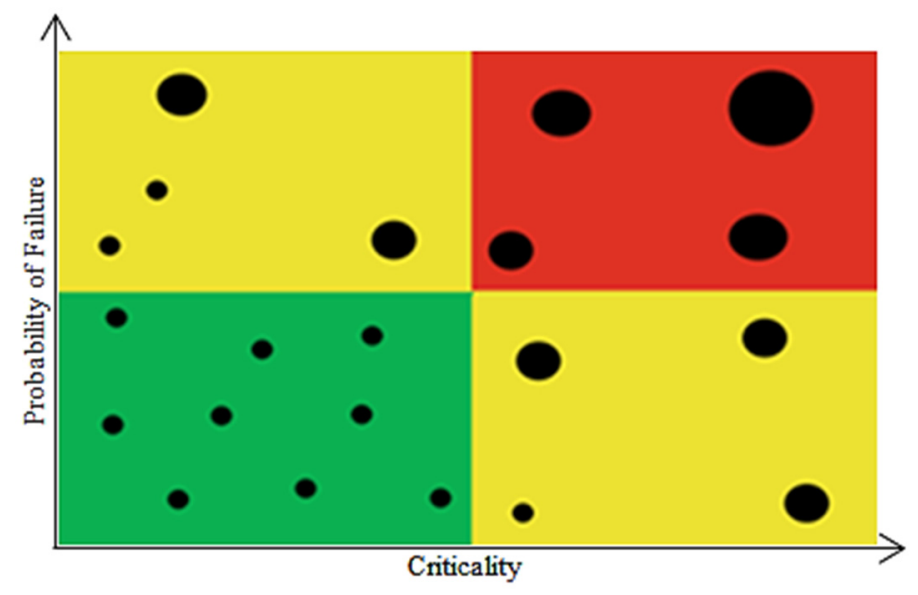

Figure 1: Risk map in RBM strategy for energy asset management. The red zone signifies a call for urgent maintenance or replacement of an asset. The two yellow zones mean that the condition of energy assets should be monitored online or offline and that preventive maintenance is performed as per plan (depending on the failure probability ranking or the asset criticality ranking). The green zone means a fairly low frequency of asset servicing.

Decision making within the framework of the RBM strategy is mathematically described by a risk index that is computed by the eqn (1) [7], [22]:

$$
R I_{a}^{y}=P o F_{a}^{y} \cdot C I_{a}^{y},
$$

where $R I_{a}^{y}$ is an integral risk index; $P o F_{a}^{y}$ is the probability of asset failure; $C I_{a}^{y}$ is the index of asset criticality; $a$ is the asset being assessed; $y$ is the year of assessment.

In practice, such a risk-based approach includes the assessment of a combination of heterogeneous risks: financial, ecological, reputational, legislative risks, as well as risks associated with security and energy supply.

\subsection{Operating models of asset management in energy companies}

The development and application of operating models of energy asset management that are used as part of risk-based strategies depends a lot on the specific features of investment processes in an energy company, as well as its preparedness for change. We shall take a look at the evolution of those models [7], [14].

The "Grid Expansion" model is usually applied by utilities that are in a stage of intense grid growth. In this case, all energy asset management decisions, including those on capital and operational expenditures are made locally (for example by construction and operations and maintenance (O\&M) departments) without preliminary planning. Decisions are dominated by technical rather than economic criteria, which is a significant drawback of the 
strategy as that could lead to over-maintenance, excessive corrective maintenance or replacing too early etc. Time-based maintenance is the dominant strategy, and risk is not managed.

In the "Performance-driven" model, decisions are made by a dedicated asset management team that proceeds from multi-year and multicriterial technical, economic and qualitative asset assessment. This model traditionally raises competition between the asset management unit and the O\&M department. This eventually leads to more innovative and effective maintenance of energy assets. Condition-based maintenance is the dominant strategy, and the model is a step further from the "Grid Expansion" model. According to experts [7], the key problem is a decentralized information management, which slows down engineering and managerial decision making.

The "Total expenditure (TOTEX)-oriented" model implies the integration of strategic asset management functions and asset maintenance into one system. The O\&M department retains only operations management functions, being accountable for:

- Long-term maintenance and replacement planning;

- Dispatching of maintenance works;

- Capital and operational expenditures management;

- Management of engineering activities on energy projects.

The adoption of the model means a transition to risk-based asset management depending on digital transformation and artificial intelligence. The actual adoption of the TOTEXoriented model by energy companies entails setting up an analytics team for mathematical risk modelling, deployment of asset management software and geographic information system.

The "Portfolio Management" model is the most modern asset management model that integrates operational asset management with long-term energy infrastructure development planning (for example, of a municipal power grid). The asset management team becomes the key unit in the operational model. There is a synergy between asset data analytics and grid modelling that requires the use of stochastic and probabilistic risk assessment models to support a transition to asset maintenance on the basis of real-time data.

To develop a "Portfolio Management" model the following actions need to be taken [7]:

1. Internal reorganization of teams and processes;

2. Design of coherent decision-making models aligned with the regulatory regime;

3. Digitalization of assets and adoption of data analytics systems.

\section{PRODUCTION ASSET MANAGEMENT PRACTICES IN RUSSIAN ENERGY COMPANIES}

We shall study the experience of the Sverdlovsk Oblast transmission system operator that is a subsidiary of PJSK "FGC UES", one of the world's largest utilities by line length and transformer capacity, in managing energy assets by applying a risk-based strategy.

The company operates $6,648 \mathrm{~km}$ of 220 to $500 \mathrm{kV}$ transmission lines, 32 substations with operating voltages from 220 to $500 \mathrm{kV}$; the total transformer capacity is 4,590 megavoltampere. The subsidiary's service area covers Sverdlovsk Oblast with a population of around 4.5 million and a surface area of 195,000 square kilometres, and Kurgan Oblast with a population of 1.02 million and a surface area of 71,500 square kilometres. The subsidiary employs 671 workers, 269 of them being production personnel who carry out maintenance works on substation equipment and high-voltage transmission lines. 
Structurally, RJSC "FGC UES" is part of the Rosseti group of companies that pulls together high-voltage, medium-voltage and low-voltage grid assets nationwide. Many of the production asset management principles that are in place within PJSC "FGC UES" are, therefore, adhered to by many other grid companies in Russia.

\subsection{Production asset management system at PJSC "FGC UES"}

The main functions of the production asset management system consist in designing a policy, goals and processes for asset management. The management processes are, in turn, divided into core, support and control ones.

Core processes are the processes of planning maintenance and repairs, retrofitting and remanufacturing of assets, performance assessment. Control processes include strategic planning of asset management and a system of key productivity indicators (KPIs), management of spending caps, asset and work data management. Support processes for production asset management include IT infrastructure management and policy framework management.

Fig. 2 presents a visual summary of the processes. For delivering high-quality automation of production asset management processes, a centralized system of regulatory and reference information was created. The regularly updated system stores structured regulatory information and reference data. Regulatory base management ensure high efficiency of production asset management throughout the entire asset lifecycle.

The assessment of the technical condition of assets delivers a list of production assets for inclusion in maintenance, repair and overhaul programs and rehabilitation programs. Program and project design management constitutes a subsystem that serves as a foundation for investment project planning and performance assessment.
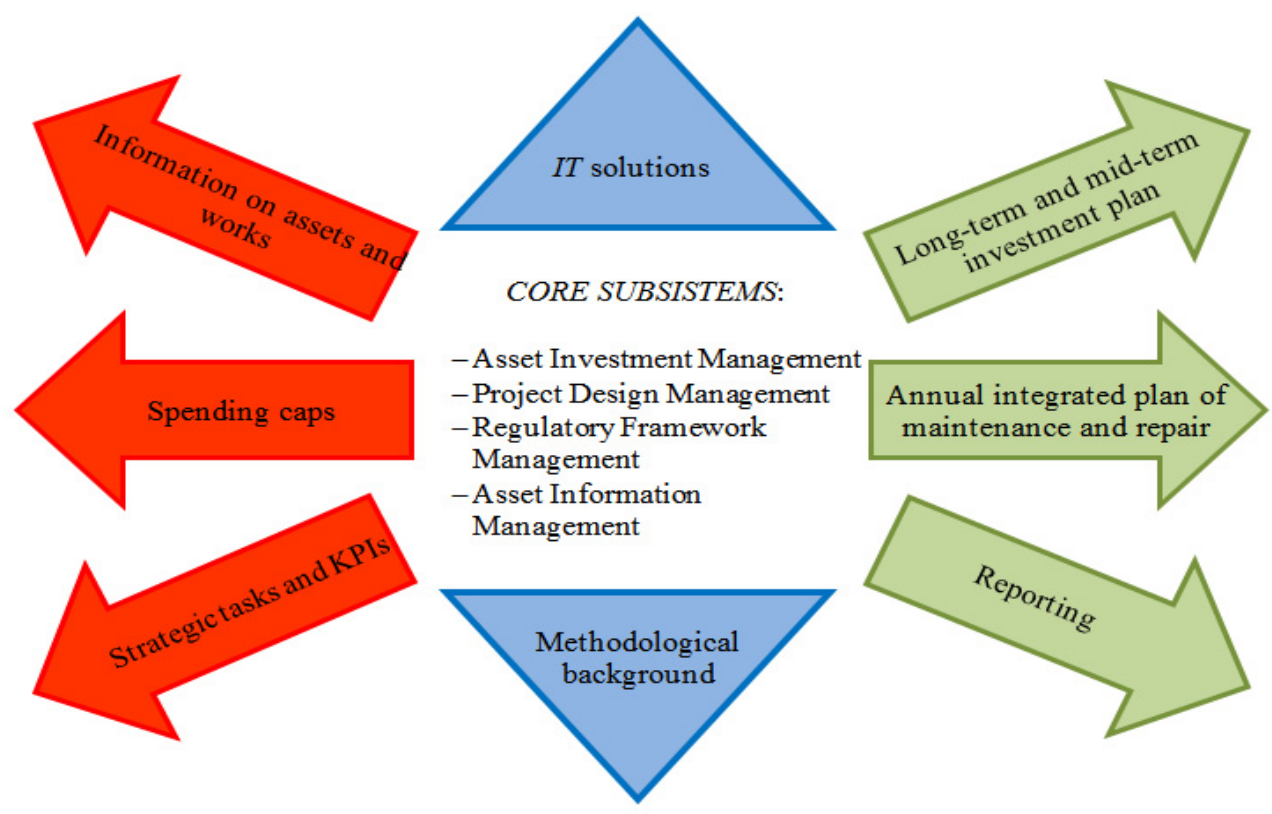
maintenance and repair

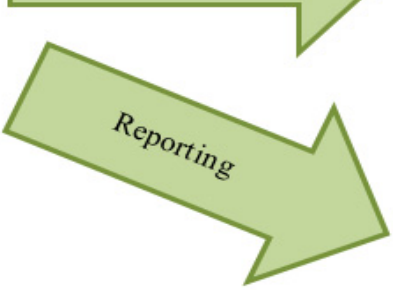

Figure 2: PJSC "FGC UES” production asset management concept. 
The "Asset Investment Management" subsystem addresses the task of effective work allocation over assets with regard to existing constraints. A decision on asset treatment is made after striking an optimum balance of costs, regulatory compliance, the prospects of grid expansion and the risks of a drop in the reliability of electricity supply. The "Asset Information Management" system is essential for managerial decision making on the basis of up-to-date, complete and plausible information on the qualitative and quantitative condition of assets.

Methodologically, the system is built upon:

- A technical condition assessment method that takes into account the existing regulations and guidelines to accomplish an integral assessment of the technical condition of assets and compute index values for each unit of equipment;

- A method of failure impact assessment that takes into account various risks (economic, social, ecological, regulatory ones) in order to assess the significance of the impact of a failure of a piece of equipment;

- A method of elaborating a production program that takes into account values delivered by the two methods above and a prioritized list of equipment. It has to be noted that certain units of equipment owned by PJSC "FGC UES" are in a state of deterioration that prevents the company from fully giving up the time-based preventative maintenance policy. Such equipment accounts for about $30 \%$ of all assets.

\subsection{Technical condition assessment algorithms}

For the sake of a unified approach to computing the technical condition index across Rosseti and FGC UES, a method of assessing the technical condition of the core grid equipment was designed that is in accordance with the peculiarities of grid infrastructure.

Production assets typically consist of numerous subsystems, with each subsystem being defined by condition indicators and various types of failures and flaws. The subsystem condition is characterized by criteria, while the assessment value of a criterion indicates fluctuations in the subsystem condition. Each subsystem is described by a set of parameters. The combination of criteria and parameters that have an impact on the technical condition of an asset make up a condition index.

By establishing links between parameters within a subsystem and assigning expertdefined weight coefficients, unified technical condition assessment algorithms were designed that can be applied regardless of the asset location and personnel qualification level.

A simplified scheme of performing a technical condition assessment of an oil circuit breaker is presented in Fig. 3. As shown in Fig. 3, to calculate the technical condition index, on the one hand, an assessment of the significance of the actual operation time of the equipment is used, and on the other hand, an assessment of the current state (physical wear) of individual elements of the oil circuit breaker is required: for example, the contact system, insulation, commutators. The red squares show the main technical characteristics of these elements, the low level of which negatively affects the quality of the equipment as a whole.

Of course, the objectivity of the calculation largely depends on the weights assigned to each element of equipment. Therefore, at the preliminary stage of technical condition assessment, much attention should be paid to the formation of an expert group, which includes the most qualified engineers, economists and managers. 


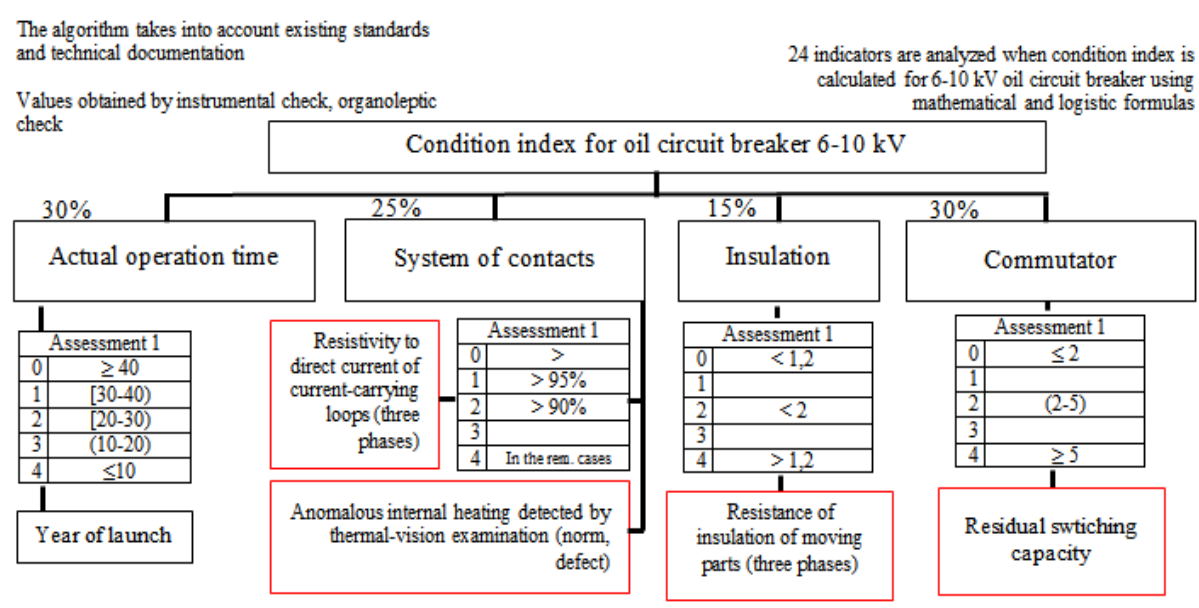

Figure 3: Forming an assessment of the technical condition of equipment.

To register the required actions ensuring the adequate functioning of an asset in the technical condition assessment algorithms, the notion of "flag" was introduced. The flag serves as an indicator showing that a piece of equipment needs treatment. When computing the technical condition index, flags were used that determined the type of treatment: maintenance, more-frequent-than-usual inspections, running maintenance, intermediatelevel maintenance, major repairs, emergency repairs, replacement, clearing and extension of the routes of overhead transmission lines. For the sake of unambiguous interpretation, the results of technical condition index computation were cast to a dimensionless value of 0 to 100 .

\subsection{Key technical solutions for implementation of production asset management system}

The implementation of a production asset management system would be impossible without production process automation. The technical foundation for the implementation of production asset management systems was provided by automated control systems found in the system analysis and program development enterprise resource planning (SAP ERP) environment. Fig. 4 presents the authors model developed for planning maintenance and repair based on SAP ERP.

At the present stage of development, production asset management systems provide technical directors with statistics on the composition of production assets, their technical condition, timeliness of equipment maintenance, costs incurred due to the repairs and maintenance program.

Planning repair and maintenance in an SAP-based automated asset management system is preceded by an overall assessment of the technical condition of assets (equipment). The assessment results are used for compiling a planned maintenance sheet for each unit of equipment.

The next step is the creation of maintenance work orders that specify the volume of work in physical terms and spell out the scope of work and determine the actual volume of work on the basis of the planned maintenance sheet that was compiled earlier. Maintenance work orders are created with the help of a planning tool that allows for creating work orders for a facility (the origin of costs) in the existing equipment structure. 


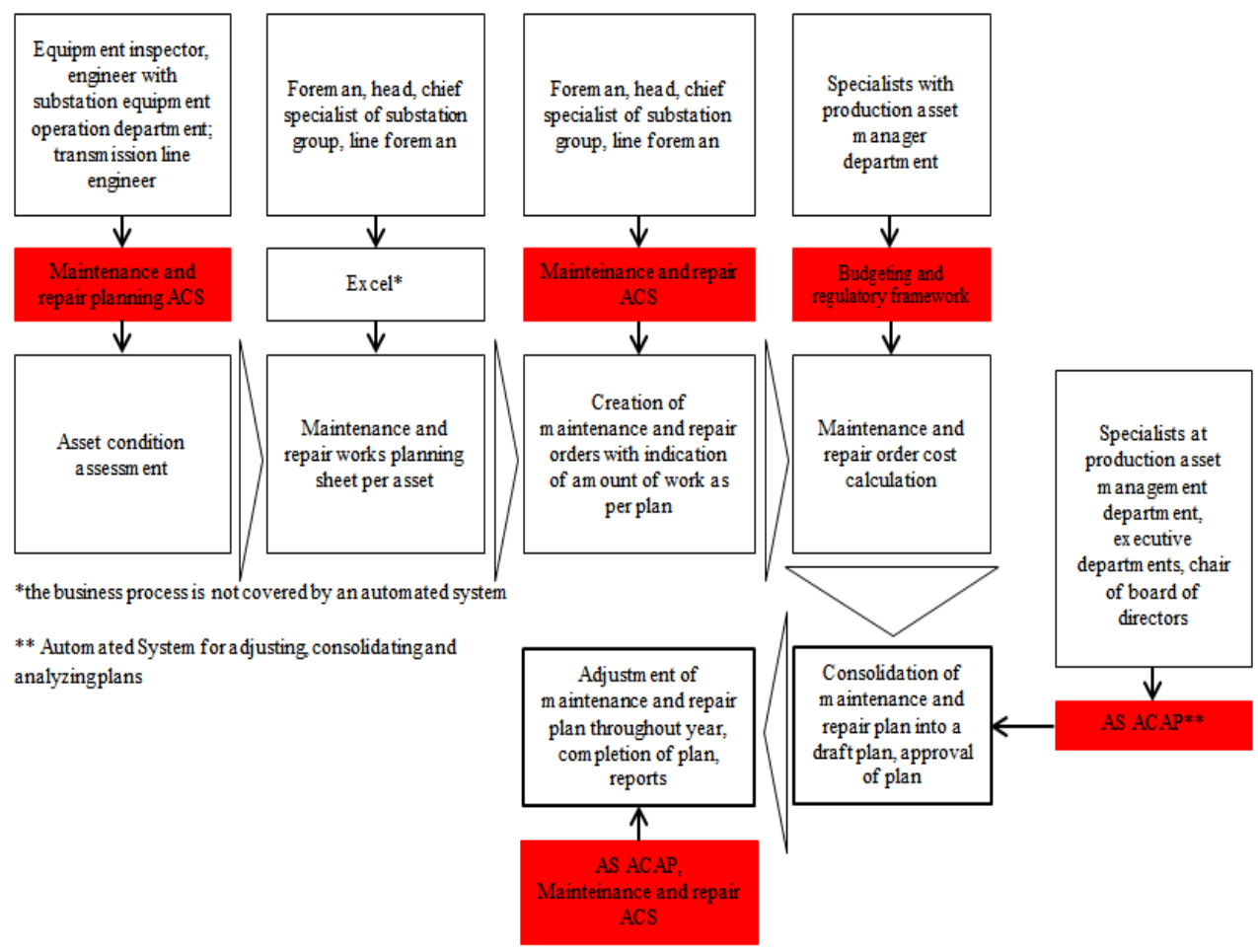

Figure 4: Model of maintenance and repair planning on the basis of SAP ERP.

The next stage of order processing is the introduction of planned rates of pay and bonuses for each category of maintenance personnel and the drawing-up of a budget proceeding from the costing standards database.

All active orders that are been created are consolidated in a run-time version of the plan that is accessible by users at any time and from any workstation that has SAP software. A user can also check the progress of the plan to a detail as small as an individual connection. This version of the plan goes through an approval process that is executed by an automated system for adjustment, consolidation and analysis of repair and maintenance plans.

The approved repair and maintenance plan is the main document for organizing repair and maintenance activities. Throughout the year, orders are closed following the signing of an acceptance report. After that, the automated repair and maintenance management system shows the actually accomplished work in physical terms and the relevant costs of repair and maintenance.

Approbation of the model proposed by the authors in PJSC "FGC UES" allowed achieving the following positive results:

- A unified procedure was introduced for calculating the required manpower and material and technical resources, machines and hardware for repair and maintenance works in accordance with the rules and guidelines that exist in the company and the industry. 
- Complete transparency was ensured as regards the cost of maintenance and repair at all levels of the corporate hierarchy (from the company to the executive team) and the risk of cost overestimation was eliminated.

- Paperwork was reduced of the processes of plan approval and preparation and approval of reports on maintenance and repair plan completion.

- Better control over the validity of expenditures.

- Financial and technical forms of subsidiaries that are needed for budget approval and adjustment are created automatically.

\section{CONCLUSIONS}

Up-to-date and accurate information about the condition of assets is the foundation for making well-considered managerial decisions, which eventually guarantees greater reliability of power supply to end users.

In this paper, the authors reviewed the progressive asset management systems for energy companies based on the risk-oriented strategies. Such systems are gradually being implemented in the Russian energy sector. Thus, the power grid company PJSC "FGC UES" develops the algorithms for evaluating the technical condition of equipment, methodological guidelines for the formation of production and repair programs that take into account the results of this assessment, as well as automation of planning, budgeting and monitoring of operational and repair activities. The proposed model based on the SAP ERP system allowed in 2018-2019 to significantly reduce the volume of document flow, improve the accuracy of economic calculations and the objectivity of decisions on the repair and renewal of fixed assets of the enterprise.

Despite a number of positive results achieved in the process of creating a production asset management system in PJSC "FGC UES", there are still plenty of issues that require further elaboration and improvement of the methodology. The authors consider the following issues highly promising for future research:

- Drafting of industry-specific scientific and technical documentation on the subject of production asset management with due consideration given to technical condition assessment, probability and impact of equipment failures.

- Integration and merger of various IT systems at various hierarchical levels (supervisory control and data acquisition, geographical information system, order management system, document management system, advanced metering infrastructure etc.).

- Development of digital forecasting and planning models supporting the making of complex decisions on production, processes and engineering (digital twin, Big Data, artificial intelligence, machine learning).

- Greater precision of outcome indicators that are used for benchmarking.

- Implementation of algorithms of building up emergency reserves and speeding up the procurement of materials and equipment for urgent condition-based repairs.

\section{ACKNOWLEDGEMENT}

The work was supported by Act 211 of Government of the Russian Federation, contract No. 02.A03.21.0006. 


\section{REFERENCES}

[1] REDSYS. Managing physical assets in the energy sector: effective import substitution [Upravlenie fizicheskimi aktivami $\mathrm{v}$ energetike: effektivnoe importozameshchenie]. http://www.redsys.ru/media/company/upravlenie-fizicheskimi-aktivami-venergetike-effektivnoe-importozameshchenie/. Accessed on: 10 May 2020.

[2] Wijnia, Y., de Croon, J. \& Liyanage, J.P., Towards an asset management reference model: Basis for a unified approach. Proceedings of the Sixth World Congress on Engineering Asset Management, Lecture Notes in Mechanical Engineering, pp. 331338, 2014.

[3] International Organization for Standardization (ISO) 55000, Asset management Overview, principles and terminology. https://www.iso.org/ru/standard/55088.html. Accessed on: 9 May 2020.

[4] Gitelman, L.D., Kozhevnikov, M.V. \& Gavrilova, T.B., Managing productive assets of energy companies in periods of crisis. Challenges and Solutions in the Russian Energy Sector, eds S. Syngellakis \& C. Brebbia, Springer: Cham, pp. 55-61, 2018.

[5] Al-Qallaf, Y.E., Owayed, F. \& Rao, P., Efficient energy management system at Kuwait Oil Company, Kuwait, a case study. International Journal of Energy Production and Management, 2(4), pp. 352-359, 2017.

[6] Kozhevnikov, M., Gitelman, L., Magaril, E., Magaril, R. \& Aristova, A., Risk reduction methods for managing the development of regional electric power industry. Sustainability, 9, 2201, 2017.

[7] Moreira da Silva, M., Asset management transformation. Power and Gas Asset Management, Lecture Notes in Energy, vol. 72, Springer Nature: Cham, pp. 89-118, 2020.

[8] Mokhov, V.G. \& Chebotareva, G.S., Research of default risk level of Russian energy. Bulletin of the South Ural State University, Series: Mathematical Modelling, Programming and Computer Software, 12(2), pp. 166-171, 2019.

[9] Chebotareva, G., Individualization of risks diagnostics in assessment of investment potential of sectoral companies in developing countries. International Journal of Sustainable Development and Planning, 13(6), pp. 851-859, 2018.

[10] Hastings, N.A.J., Physical Asset Management. With an Introduction to ISO55000, Springer: Berlin, pp. 43-57, 2015.

[11] Baglee, D. \& Knowles, M.J., Developing RCM strategy for wind turbines utilizing online condition e-monitoring. Proceedings of the Sixth World Congress on Engineering Asset Management, Lecture Notes in Mechanical Engineering, pp. 1120, 2014.

[12] Tiusanen, R., Jännes, J. \& Liyanage, J.P., From-design-to-operations risk mitigation in Nordic wind energy assets: A systematic RAMS+I management model. Proceedings of the Sixth World Congress on Engineering Asset Management, Lecture Notes in Mechanical Engineering, pp. 365-383, 2014.

[13] Cheng, Z., Jia, X., Gao, P., Wu, S. \& Wang, J., A framework for intelligent reliability centered maintenance analysis. Reliability Engineering and System Safety, 93, pp. 784-792, 2008.

[14] Abbas, M. \& Shafiee, M., An overview of maintenance management strategies for corroded steel structures in extreme marine environments. Marine Structures, 71, 102718, 2020.

Shafiee, M. \& Sørensen, J.D., Maintenance optimization and inspection planning of wind energy assets: models, methods and strategies. Reliability Engineering and System Safety, 192, 105993, 2019. 
[15] Shafiee, M., Maintenance strategy selection problem: an MCDM overview. Journal of Quality in Maintenance Engineering, 21(4), p. 378, 2015.

[16] Ahmad, R. \& Kamaruddin, S., An overview of time-based and condition-based maintenance in industrial application. Computers \& Industrial Engineering, 63, pp. 135-149, 2012.

[17] Hofmann, E., Performance based logistics - A new management approach in the defense sector. Performance Based Logistics, ed. A. Glas, Springer Gabler: Wiesbaden, pp. 127-163.

[18] Bertolini, M., Bevilacqua, M., Ciarapica, F.E. \& Giacchetta, G., Development of riskbased inspection and maintenance procedures for an oil refinery. Journal of Loss Prevention in the Process Industries, 22, pp. 244-253, 2009.

[19] Scheu, M.N., Tremps, L., Smolka, U., Kolios, A. \& Brennan, F., A systematic failure mode effects and criticality analysis for offshore wind turbine systems towards integrated condition based maintenance strategies. Ocean Engineering, 176, pp. 118133, 2019.

[20] Rasmekomen, N. \& Parlikad, A.K., Maintenance optimization for asset systems with dependent performance degradation. Proceedings of the Sixth World Congress on Engineering Asset Management, Lecture Notes in Mechanical Engineering, pp. 6776, 2014.

[21] Moreira da Silva, M., Decision models and advanced analytics. Power and Gas Asset Management, Lecture Notes in Energy, 72, Springer Nature: Cham, Chapter 5, 2020. 